\title{
Development and Characterization of Biobased Alginate/Glycerol/Virgin Coconut Oil as Biodegradable Packaging
}

\author{
Adinda Dwi Putri Marismandani, and Amir Husni* \\ Department of Fisheries, Faculty of Agriculture, Universitas Gadjah Mada, Yogyakarta 55281, \\ Indonesia
}

\begin{abstract}
Plastics are widely used as packaging materials but can cause environmental problems because they are not easily degraded. Therefore, it was necessary to find alternative packaging materials that were easily degraded, including edible film. The main raw materials for edible film were alginate and plasticizers including glycerol and virgin coconut oil (VCO). The aims of this study were to determine the characteristics of edible films composed of alginate, glycerol and VCO and to determine the best concentration of alginate in edible films. The study was carried out through the manufacture of edible films composed of alginates at various concentrations $(2,3,4,5$ and $6 \%), 10 \%$ glycerol and $0.01 \%$ VCO. The characteristics observed included thickness, tensile strength, elongation, solubility, and water vapor transmission rate (WVTR). The results showed that increasing the concentration of alginate increased the thickness, tensile strength, and elongation of edible films but reduced the solubility and WVTR of edible films. The best alginate concentration was $4 \%$ with the following characteristics: thickness, $0.12 \pm 0.01 \mathrm{~mm}$; tensile strength, $1.59 \pm 0.12 \mathrm{MPa}$; elongation, $48.73 \pm 1.97 \%$; solubility, $92.07 \pm 0.57 \%$; and WVTR, $49.18 \pm 0.59 \mathrm{~g} / \mathrm{m}^{2} .24$ hours. The various alginate concentrations significantly affected the thickness, tensile strength, elongation, and water vapor transmission rate of the edible film produced.
\end{abstract}

\section{Introduction}

Recently, the use of plastic is very broad, and Indonesia produced 187.2 million tons of garbage in 2015 [1]. Plastics as packaging materials have various advantages, i.e. flexible, easily formed, and the price is relatively cheap and affordable for all people. However, plastic is not easily degraded by the environment, either by weather, rain, solar heat, or microbes that live in the soil, causing pollution to the environment.

* Corresponding author : a-husni@ugm.ac.id 
Edible films made from alginate are one of the solutions to environmental pollution problems caused by the widespread use of plastic. According to [2], the use of alginate as the basic ingredient in edible films provides the advantages of being able to protect products against oxygen, oil, and carbon dioxide, and improve the unity of the product structure. However, in addition to having advantages, edible alginate film has disadvantages, such as the film is easily damaged when dried, has a poor ability to regulate water vapor migration, and has weak mechanical strength. This is because alginate has a hydroxyl group that is negatively charged; thus, the bonds between molecules are weak [3]. Therefore, plasticizers are needed to reduce their weaknesses.

Based on research conducted by [4], the addition of VCO and glycerol had an effect on the percent of elongation of the edible film. Based on the results obtained from the combination of VCO and glycerol on the characteristics of edible film from palm starch, research is needed on the combination of various concentrations of VCO and glycerol against the characteristics of alginate-based edible film as a plasticizer agent.

\section{Materials and methods}

\subsection{Preparation of edible film}

The production of alginate edible film based on the method of [5] with modification. Treatments used were various concentrations of sodium alginate, namely, 2\%, 3\%, 4\%, 5\%, and $6 \%(\mathrm{w} / \mathrm{v})$. The alginate solution was stirred until homogeneous at room temperature, then, $10 \%$ glycerol was added, followed by the addition of $0.01 \%$ virgin coconut oil (VCO), which had been dissolved in pure ethanol. The mixture was stirred until homogeneous using a hot plate stirrer for 3 hours. Afterward, alginate was molded on a glass plate with dimensions of $15 \mathrm{~cm} \times 20 \mathrm{~cm}$ and a thickness of $0.3 \mathrm{~mm}$. The mold was dried at $50{ }^{\circ} \mathrm{C}$ for 24 hours. After drying, the film was soaked in a $4 \% \mathrm{CaCl}_{2}$ solution and then rinsed with distilled water. The film was dried in an oven for 24 hours. Dry film was removed from the glass plate and stored in a closed container with silica gel to prevent moisture absorption to the film. The characteristics of the film were measured.

\subsection{Characterization of edible film}

\subsubsection{Thickness}

The method for measuring thickness was described by [6]. The film thickness was measured using a micrometer with a precision of $0.0001 \mathrm{~mm}$. Measurements were made at five different points to obtain the average thickness representing the sample.

\subsubsection{Tensile strength}

The tensile strength analysis method was carried out based on [8] using a universal testing machine. Analysis was performed by cutting the sample into a paddle shape, and then the tip of the sample was clamped by the tensile testing machine. The thickness and initial length of the sample were recorded. When the machine was operated, the probe pulled the sample at a speed of $100 \mathrm{~mm} / \mathrm{min}$ until the sample broke. The tensile strength value was obtained by determining the maximum stress distribution of the cross-sectional area. The cross-sectional area was obtained by multiplying the initial length of the sample by the initial thickness of 
the sample. The analyses were performed in duplicate. The tensile strength was calculated as follows:

$$
\tau=\frac{F \max }{A}
$$

$$
\begin{aligned}
& \text { Noted: } \quad \tau \quad=\text { tensile strength }(\mathrm{MPa}) \\
& \mathrm{F}_{\max }=\text { maximum voltage }(\mathrm{N}) \\
& \text { A }=\text { cross sectional area }\left(\mathrm{mm}^{2}\right)
\end{aligned}
$$

\subsubsection{Elongation}

Elongation measurements were carried out based on [8] in the same way as the tensile strength analysis. Extension was expressed as a percentage, calculated as follows:

$$
\text { Elongation }(\%)=\text { breaks length } / \text { initial length } \times 100 \%
$$

\subsubsection{Total Soluble Matter}

Solubility testing was carried out based on [5] and expressed as a percentage of dry weight of the film dissolved in distilled water for 24 hours. Parts of each sample (m0) were weighed with an accuracy of $\pm 0.0001 \mathrm{~g}$ and then immersed in $30 \mathrm{ml}$ of distilled water for 24 hours. After soaking, the sample was dried at $105^{\circ} \mathrm{C}$ for 24 hours to measure the weight of the insoluble material (mf). Solubility calculations are carried out with the following calculations:

$$
\operatorname{TSM}(\%)=\frac{m 0-m f}{m 0} \times 100
$$

\subsubsection{Water vapor transmission rate}

The vapor transmission rate of the edible film (gram.mm/m2.hari) was measured using the cup method determined gravimetric according to the ASTM E96-01 [9] method. Before being measured, the edible film was cut into a circle with a diameter according to the surface diameter of the cup. The thickness of the film was measured using a micrometer and then conditioned in a room with a temperature of $25^{\circ} \mathrm{C}$ and relative humidity (RH) $75 \%$ for 24 hours.

\section{Results and discussion}

\subsection{Thickness of the edible film}

The thickness of edible film is one of the physical properties of edible film that is influenced by the concentration of soluble edible film and the size of the edible film glass plate. According to [10], thickness also greatly influences the physical and mechanical properties of edible films, such as tensile strength, elongation, and water vapor transmission rate (WVTR). 
Table 1. Effect of alginate concentration on the characteristics of composite alginate/glycerol/virgin coconut oil edible film

\begin{tabular}{|l|c|c|c|c|c|}
\hline $\begin{array}{c}\text { Alginate } \\
(\%)\end{array}$ & $\begin{array}{c}\text { Thickness } \\
(\mathrm{mm})\end{array}$ & $\begin{array}{c}\text { Tensile } \\
\text { strength } \\
(\mathrm{MPa})\end{array}$ & Elongation $(\%)$ & $\begin{array}{c}\text { Total soluble } \\
\text { matter }(\%)\end{array}$ & $\begin{array}{c}\text { WVTR } \\
\left(\mathrm{g} / \mathrm{mm}^{2} / 24\right. \\
\text { hours })\end{array}$ \\
\hline 2 & $0.030 \pm 0.033^{\mathrm{c}}$ & $3.756 \pm 0.828^{\mathrm{a}}$ & $37.856 \pm 1.532^{\mathrm{d}}$ & $2.306 \pm 0.500^{\mathrm{c}}$ & $52.563 \pm 0.500^{\mathrm{c}}$ \\
\hline 3 & $0.104 \pm 0.005^{\mathrm{b}}$ & $1.646 \pm 0.204^{\mathrm{b}}$ & $44.607 \pm 2.528^{\mathrm{c}}$ & $2.893 \pm 0.254^{\mathrm{c}}$ & $49.963 \pm 0.254^{\mathrm{bc}}$ \\
\hline 4 & $0.125 \pm 0.012^{\mathrm{ab}}$ & $1.745 \pm 0.088^{\mathrm{b}}$ & $48.732 \pm 1.973^{\mathrm{bc}}$ & $3.920 \pm 0.597^{\mathrm{c}}$ & $49.186 \pm 0.597^{\mathrm{bc}}$ \\
\hline 5 & $0.149 \pm 0.009^{\mathrm{ab}}$ & $0.615 \pm 0.146^{\mathrm{b}}$ & $57.477 \pm 2.757^{\mathrm{ab}}$ & $5.744 \pm 0.306^{\mathrm{b}}$ & $48.402 \pm 0.306^{\mathrm{b}}$ \\
\hline 6 & $0.18 \pm 0.005^{\mathrm{a}}$ & $0.929 \pm 0.486^{\mathrm{b}}$ & $66.084 \pm 2.514^{\mathrm{a}}$ & $8.072 \pm 0.246^{\mathrm{a}}$ & $47.648 \pm 0.246^{\mathrm{a}}$ \\
\hline Standard & Max 0.25 & Min 3.92 & Min 10 & & Max 10 \\
\hline
\end{tabular}

Note: The same letter in the same line indicates no significant difference $(p>0.05)$.

Table 1 shows that the thickness of the edible film produced increases with the increase in alginate concentration. The alginate concentration had a significant effect on the thickness of the edible film $(\mathrm{p}<0.05)$. According to [10], the most important factor that influences film thickness is the concentration of dissolved solids in the film-forming solution and the size of the printing glass plate. The more dissolved solids, the thicker the edible film will become. Compared to the other alginate concentrations, the greatest thickness occurred at $6 \%$ alginate, which was $0.18 \mathrm{~mm}$. This is in accordance with [11], who showed that edible film mixtures containing the maximum composition of material will yield a very thick solution, with a thickness greater than the other compositions. This is also supported by [12], who stated that the higher the hydrocolloid concentration (such as corn and black meeting juice) the thicker the edible film will become. This is thought to be related to the higher concentration of the constituent components of the edible film, which will increase the total solids, increasing the thickness of the edible film. Increasing the concentration of the material used will increase the total solids contained in the edible film after drying so that it will produce a thicker film. [13] also stated that the higher the thickness value, the stiffer and harder the edible film will become, and the products packaged with these edible films will be more secure from outside influences.

The thickness value in this study is close to the results of [14], [15] and [12]. Based on the results of the edible film thickness produced in this study, when compared to the Japanese Industrial Standard [16], the thickness of the edible film is still relatively good because it is still below the standard (maximum thickness of edible film is $0.25 \mathrm{~mm}$ ).

\subsection{Tensile strength}

Tensile strength is a measure of the strength of edible film specifically and is the maximum pull that can be achieved until the film breaks [17]. Table 1 shows that the alginate concentration has a significant effect on the tensile strength. Factors that influence the tensile strength can be caused by the addition of $\mathrm{CaCl}_{2}$. The addition of $\mathrm{CaCl}_{2}$ as a cross-linking agent causes $\mathrm{Ca}^{2+}$ ions to increase the cohesion force, barrier properties, and mechanical strength of alginate edible films [18]. This is also supported by [2], who showed that the tensile strength was low at a concentration of $1 \%$ due to the influence of castor oil interference with $\mathrm{Ca}^{2+}$ ions responsible for ionic interactions and the formation of cross- 
linked networks. According to [2], alginate films have disadvantages, namely, weak mechanical strength because alginate only has a hydroxyl group that is negatively charged; therefore, the bonds between molecules are weak. This influences mechanical values, such as low tensile strength. Another factor that causes a decrease in the tensile strength is the type of constituent material. In making this edible film, hydrocolloid (in the form of alginate), lipid (in the form of virgin coconut oil), and glycerol as plasticizers were used.

The addition of lipids, such as virgin coconut oil in the manufacture of hydrocolloid edible film, will reduce the tensile strength because lipids do not have good solubility in water, which is needed when making edible film (hydrophobic) solutions. Lipid properties are nonpolar, so they cannot dissolve well with polar water. This results in a bond that is not formed properly and decreases the tensile strength. This is also supported by [11]; the addition of lipids such as fatty acids and their derivatives will reduce this tensile strength because lipids do not have good solubility in water when making edible film (hydrophobic) solutions. Lipid properties are nonpolar, so they cannot dissolve well with polar water. This results in a bond that is not formed properly and decreases the tensile strength.

According to [19], the presence of plasticizers can increase the flexibility of polymer chains. The type of plasticizer used in this study was glycerol, which has a small molecular weight, making it easy to enter between hydrogen alginate bonds. Glycerol molecules will disrupt the compactness of the alginate matrix, reduce intermolecular interactions and increase polymer mobility, resulting in an increase in tensile strength [20]. Based on this statement, supplementing film solutions with $10 \%$ glycerol v/v decreases the tensile strength. This is consistent with the research of [21]. Compared with the Japanese Industrial Standard [16], it can be said that the tensile strengths of the edible films made with all alginate concentrations in this study still meet the standard (minimum 0.392 $\mathrm{MPa}$ ).

\subsection{Elongation}

Extension (elongation) is the addition of the length of film material from the initial length at the time of withdrawal until it breaks. As reported by [22], the characteristics of standard edible film have a percentage of elongation between 10-50\%. Based on Table 1, the elongation value of the edible film produced increased with the increase in alginate. This increase in the elongation value is due to the increase in dissolved solids in the edible film forming solution so that the thickness of the edible film produced increases. According to [23], an increase in the thickness of edible film is also related to the nature of colloidal compounds that are unique, such as thickeners and suspenders, and the interaction between the components of edible film. In addition, [24] stated that the thickness of edible film tends to increase with increasing carrageenan and glycerol concentrations. When compared with the Japanese Industrial Standard [16], the percentage of elongation is categorized as bad if it is less than $10 \%$ and is categorized as very well if the percentage is more than $50 \%$. Based on this, the edible film in this study is said to be good.

\subsection{Total soluble matter}

Table 1 showed that the value of the water vapor transmission of the edible film produced decreases with the increase in alginate concentration. The higher the alginate concentration that was used, the higher the solubility value was. This is because an increase in the number of hydrophilic components can cause a high percentage increase in film solubility. In this case, the hydrophilic component used was alginate [25]. Film solubility is an important factor that determines the biodegradability of films when used as packaging wrappers [26]. Table 1 shows that the lowest solubility was at $2 \%$ alginate, which is equal to $2.3063 \%$, while the highest solubility was at $6 \%$ alginate, which is $8.072 \%$. 


\subsection{Water vapor transmission rate}

The water vapor transmission rate (WVTR) is the rate of the transmission of water vapor through a unit of material that has a flat surface with a certain thickness as a result of a different unit of water vapor pressure between certain surfaces at certain conditions and temperatures [22]. The WVTR test results can be seen in Table 1, which shows that the WVTR value of the edible films produced decreased with the addition of alginate. The higher the alginate concentration, the smaller the WVTR value was. This is supported by [27], who stated that the high concentration of an edible film will increase the number of film-forming polymers and total solids, forming thick edible films. Increasing the number of polymers will reduce the cavity in the gel formed; the thicker and denser the matrix of the film, the more the rate of water vapor will be reduced because it is difficult to penetrate the water vapor. The best alginate concentration was $4 \%$ with the following characteristics: thickness, $0.12 \pm 0.01 \mathrm{~mm}$; tensile strength, $1.59 \pm 0.12 \mathrm{MPa}$; elongation, $48.73 \pm 1.97 \%$; solubility, $92.07 \pm 0.57 \%$; and WVTR, $49.18 \pm 0.59 \mathrm{~g} / \mathrm{m}^{2} .24$ hours.

\section{Conclusion}

In the manufacture of edible films from alginate, glycerol, and virgin coconut oil composites, the alginate concentration significantly affected the thickness, tensile strength, elongation (extension), water vapor transmission rate, and solubility of the edible film.

\section{References}

1. Jambeck. R, Jenna. Plastic waste inputs from land into the ocean. University of Georgia. University of Georgia (2015)

2. M. Sabaa, Abdel, E.S. Hend, W. Magdy W, LWT. Chemistry Departement Faculty of Science. Cairo University. Giza. Egypt (2018)

3. S. Chillo, Flores S, Mastromatteo M., Conte A., Gerschenson L., dan Del Nobile M.A. Journal of Food Engineering 88, 159-168 (2008)

4. P. Coniwati, Dewi P,D.M. Pratiwi. Jurusan Teknik Kimia, Fakultas Teknik. Universitas Sriwijaya. Palembang (2018).

5. N. Rokhati, Giovanni A, Y. Hidayat. Jurnal Teknologi Kimia dan Industri. 2, 51-56 (2013)

6. A. Alemán, N. B. Pascual, M.P. Montero M.C. Gómez-Guillén. Food Hydrocol (2016)

7. W. Setiani, S. Tety, R. Lena. Jurusan Kimia Fakultas Sains dan Teknologi UIN Sunan Gunung Djati Bandung Jurnal Kimia Valensi 3 (2013)

8. Pereda M, A. Guillermina, E.M. Norma. Carbohydrate Polymers 87, 1318-1325 (2012)

9. ASTM D 790. American Society for Testing and Materials, Philadelpia (2001)

10. J. Krochta, M., Baldwin, E. A., dan M., O. Nisperos-Carriedo. Edible coatings and film to improve food quality, Economic Publ. Co. Inc., USA (1994)

11. A. Prasetyaningrum, N. Rokhati, D.N. Kinasih, F.D.N. Seminar Rekayasa Kimia dan Proses. ISSN : 1411 - 4216. Seminar Rekayasa Kimia dan Proses (2010)

12. D. Kusumawati H., W.D.R. Putri. WDR. Jurnal Pangan dan Agroindustri (2013)

13. D. Jacoeb, R Nugraha. Jurnal Pengolahan Hasil Perikanan Indonesia (2014) 
14. Y. Zhang, Qiumin Ma, F. Critzer, P.M. Davidson, Qixin Zhong. Food Science and Technology (2015)

15. J. Kadzinska, Joanna Brys., E. Ostrowska-Ligeza., M. Esteve., M. Janowicz. Polymer Bulletin (2019)

16. A. Setyaningrum, Ni K. S., Jaya H. Journal of Science and Technology 6, 136-143 (2017)

17. J. Krochta, M. Aldwin, E. A., dan M., O. N. Carriedo. Edible coatings and film to improve food quality, Economic Publ. Co. Inc., USA. (1994)

18. A. Cagri, Ustunol Z, Osburn W, Ryser ET. J of Food Protection 67 (2003)

19. Y. Pranoto, Salokhe V.M, Rakshit S.K. Food and Agriculture Organization of the United Nations (2005)

20. Hasibuan, Machrani. Tesis. Universitas Sumatera Utara. Medan (2009)

21. N. Riquelme, M. L.Herrera, S. Matiacevich. Food and Bioproducts Processing. Manuscript (2017)

22. J. M Krochta, C. De Mulder-Johnston. J. Food Tech., 51 (1997)

23. S. Galus, A. Lenart. Journal of Food Engineering 115, 459-465 (2013)

24. A. Rusli, Metusalach, S.Salengke, M. Muhammad Tahir. Universitas Hasanudin (2017).

25. S.Saiful, S.Salman. Prosiding. The 3rd Annual International Conference Syiah Kuala University (AIC Unsyiah) In conjunction with The 2nd International Conference on Multidisciplinary Research (ICMR). Banda Aceh (2013)

26. R. Paramawati. (Skripsi). Institut Pertanian Bogor.Bogor (2001)

27. K.H. Dyah, W.D. Rukmi P. Jurusan Teknologi Hasil Pertanian, FTP Universitas Brawijaya Malang (2013)

28. J. J Kester, dan Fennema, O. R, J. Food Tech., 51 (1986)

29. V. Morillon, Debeaufort, F, Blond, G, Capelle, M \& Voilley, A. Critical Reviews in Food Science and Nutrition 42 (2002) 